\title{
PENDUGAAN FAKTOR PENENTU PRODUKSI PADI SAWAH SISTEM TANAM LEGOWO DI KELURAHAN DUSUN BESAR KECAMATAN GADING CEMPAKA KOTA BENGKULU
}

\author{
(DETEMINANT FACTORS OF PADDY PRODUCTION IN THE \\ LEGOWO CROPPING SYSTEM IN DUSUN BESAR VILLAGE, \\ SUBDISTRICT OF GADING CEMPAKA, BENGKULU CITY)
}

\author{
Nyayu Neti Arianti \\ Jurusan Sosial Ekonomi Pertanian \\ Fakultas Pertanian Universitas Bengkulu
}

\begin{abstract}
The aim of this research was to analyze the factors which influence the paddy production of legowo cropping system on Dusun Besar Subdistrict Gading Cempaka District Bengkulu City. The respondents were 56 farmers from 65 farmers of three types of legowo cropping system 4:1, 6:1 dan 8:1 and they were taken with Slovin Formula. The cross section data used in this research include paddy production, land size, seed, urea, labour, and the type of legowo system as dummy variables. To determine influencing factors of production, this research applied Cobb Douglass model. The research results showed that seed used is significat factor but has a negative impact on production, while urea and legowo type of 4:1 have positive and significant effect on production.

Keywords : legowo system, paddy, production function, Cobb - Douglass
\end{abstract}

\section{PENDAHULUAN}

Padi merupakan komoditas yang menyangkut hajat hidup dan kebutuhan mendasar bagi hampir sebagian besar penduduk Indonesia. Oleh karena itu usaha untuk mencapai ketahanan pangan dan swasembada beras nasional merupakan suatu keharusan (Anonim, 2009 seperti dikutip Wulansari, 2010). Pembangunan pertanian berspektrum luas yang menjadi jargon sejak tahun 1960-an memasukkan konsep "LIMA I" dalam strategi pertumbuhan pertanian. Salah satu yang termasuk dalam "LIMA I" tersebut adalah Inovasi, yaitu sistem penelitian, pengembangan dan penyuluhan pertanian (swasta dan pemerintah) yang menghasilkan dan menyebarluaskan teknologi baru untuk pengembangan produktifitas komoditi pertanian terutama padi (Arifin, 2000).

Salah satu teknologi yang dikembangkan dalam rangka meningkatkan produktifitas usahatani padi sawah adalah sistem tanam legowo. Legowo berasal dari kata "lego" dan "dowo". "Lego" artinya luas dan tumbuh lebih baik dan hasilnya lebih tinggi karena luasnya antar kelonpok barisan (lorong) biasanya mencapai $50 \mathrm{~cm}, 60 \mathrm{~cm}$ atau $70 \mathrm{~cm}$ bergantung kepada kesuburan 
tanah. Sedangkan "dowo" artinya memanjang, jadi di antara kelompok barisan tanaman padi terdapat lorong yang luas dan memanjang sepanjang barisan.

Kelurahan Dusun Besar merupakan salah satu daerah penghasil padi sawah di Kecamatan Gading Cempaka Kota Bengkulu. Dalam rentang waktu dari tahun 2003 sampai tahun 2007 produktifitas padi sawah di Keluarahan Dusun Besar mengalami peningkatan sebesar 1,36 ton/Ha. Salah satu teknologi usahatani padi sawah yang dikembangkan di Kelurahan Dusun Besar ini adalah sistem tanam legowo. Ada tiga tipe sistem tanam legowo yang digunakan petani, yaitu tipe 4:1, 6:1 dan 8:1.

Fungsi produksi usahatani adalah suatu fungsi yang menggambarkan pengaruh faktor produksi terhadap jumlah produksi (Daniel, 2002). Faktorfaktor produksi tersebut adalah lahan, tenaga kerja, modal dan manajemen. Produksi padi dipengaruhi oleh faktor-faktor produksi dalam usahatani padi antara lain luas lahan, benih, tenaga kerja, pupuk, pestisida dan teknologi. Hasil penelitian Wulansari (2010) menunjukkan bahwa produktifitas padi sawah berbeda antar sistem legowo. Produktifitas padi sawah sistem tanam 8:1 paling tinggi dibanding tipe 4:1 dan 6:1. Hal ini menunjukkan bahwa teknologi dapat meningkatkan produktifitas usahatani.

Penelitian ini bertujuan untuk mengetahui faktor-faktor yang mempengaruhi produksi usahatani padi sawah sistem tanam legowo di Kelurahan Dusun Besar Kecamatan Gading Cempaka Kota Bengkulu.

\section{METODE PENELITIAN}

Penelitian ini dilakukan di Kelurahan Dusun Besar Kecamatan Gading Cempaka Kota Bengkulu dengan pertimbangan bahwa kelurahan ini merupakan daerah penghasil padi sawah yang menerapkan sistem tanam legowo. Penelitian dilaksanakan pada bulan Nopember 2009.

Populasi dalam penelitian ini adalah petani padi sawah yang menerapkan sistem tanam legowo, yaitu sebanyak 65 orang dengan rincian tipe 4:1 sebanyak 14 orang, tipe 6:1 sebanyak 31 orang dan tipe 8:1 sebanyak 20 orang. Untuk menentukan jumlah sampel penelitian atau responden digunakan rumus Slovin dalam Wulansari (2010) sebagai berikut :

$n=N /\left(1+N e^{2}\right)$

Dimana :

$\mathrm{n}$ : Jumlah sampel ; $\mathrm{N}$ : Jumlah populasi ; e : persentase atau tingkat kesalahan Jika tingkat kesalahan ditetapkan $0,05 \%$ maka jumlah responden adalah :

$n=65 /\left(1+65(0,05)^{2}\right)$

$n=65 / 1,1625$

$n=55,91=56$ orang

Jumlah responden ditetapkan sebanyak 56 orang, sehingga secara proporsional berdasarkan sistem tanam legowo, maka jumlah reponden untuk sistem legowo 4:1 sebanyak 12 orang, sistem legowo 6:1 sebanyak 26 orang dan 
sistem 8:1 sebanyak 18 orang yang kemudian diambil secara acak dari populasi masing-masing tipe sistem tanam.

Data yang digunakan dalam penelitian ini adalah data primer dan data sekunder. Data primer menggunakan data survei yang dilakukan oleh Wulansari (2010), meliputi data produksi, luas lahan, benih, pupuk dan tenaga kerja dalam usahatani sistem tanam legowo. Data sekunder berupa data-data pendukung dan informasi yang berkaitan dengan penelitian.

Untuk mengetahui faktor-faktor yang mempengaruhi produksi padi sawah sistem tanam legowo persamaan fungsi produksi Cobb-Douglas yang kemudian ditransformasikan ke dalam bentuk persamaan double log agar dapat diestimasi dengan metode Ordinary Least Square (OLS). Persamaan matematisnya dapat disusun sebagai berikut:

$\log Y_{i}=\log a+b_{1} \log X_{1 i}+b_{2} \log X_{2 i}+b_{3} \log X_{3 i}+b_{4} \log X_{4 i}+b_{5} D_{1 i}+b_{6} D_{2 i}+u$

Dimana :

$\mathrm{Y}$ : Produksi padi $(\mathrm{kg} / \mathrm{UT}) ; \mathrm{X}_{1}$ : Luas lahan $(\mathrm{Ha}) ; \mathrm{X}_{2}$ : Jumlah benih $(\mathrm{kg} / \mathrm{UT}) ; \mathrm{X}_{3}$ : Jumlah pupuk urea $(\mathrm{kg} / \mathrm{UT}) ; \mathrm{X}_{4}$ : Jumlah tenaga kerja $(\mathrm{HOK} / \mathrm{UT}) ; \mathrm{D}_{1}$ : Variabel dummy tipe legowo 4:1 (D1 = 1 jika tipe 4:1 dan D1 = 0 jika tipe lainnya); $\mathrm{D}_{2}$ : Variabel dummy tipe legowo 6:1 $(\mathrm{D} 2=1$ jika tipe $6: 1$ dan $\mathrm{D} 2=0$ jika tipe lainnya); $a$ : Konstanta; $b_{1}-b_{6}$ : Koefisien regresi; $u$ : Kesalahan pengganggu; $i$ : Responden ke-i

Koefisien regresi hasil estimasi kemudian diuji secara statistik pada tingkat kepercayaan 95\%. Pengaruh variabel bebas secara bersama-sama terhadap variabel terikat diuji dengan Uji F. Pengaruh masing-masing variabel bebas terhadap variabel terikat secara parsial diuji dengan Uji $t$.

\section{HASIL DAN PEMBAHASAN}

\section{Karakter Responden}

Hasil penelitian menunjukkan karakter petani responden seperti tertera pada Tabel 1 berikut :

Tabel 1. Rata-Rata Karakteristik Responden Petani Sistem Legowo di Kelurahan Dusun Besar Kecamatan Gading Cempaka Kota Bengkulu

\begin{tabular}{llll}
\hline \multirow{2}{*}{ Karakter Responden } & \multicolumn{3}{c}{ Tipe Legowo } \\
\cline { 2 - 4 } & \multicolumn{1}{c}{$\mathbf{4 : \mathbf { 1 }}$} & $\mathbf{6 : \mathbf { 1 }}$ & $\mathbf{8 : \mathbf { 1 }}$ \\
\hline Umur (Tahun) & 49,67 & 42,88 & 44,11 \\
Pendidikan formal (Tahun) & 8,25 & 9,19 & 8,50 \\
Pendidikan non formal (kali) & 0,58 & 0,73 & 0,72 \\
Jumlah anggota keluarga (orang) & 5,50 & 4,38 & 4,25 \\
Pengalaman usahatani (Tahun) & 19,17 & 12,08 & 11,50 \\
\hline
\end{tabular}

Karakter petani responden sistem legowo di daerah penelitian dapat dijelaskan bahwa rata-rata umur petani pada masing-masing sistem tergolong produktif yakni rata-rata berkisar antara 49,67, 42,88, dan 44,11 tahun. Usia

12 | Nyayu Neti Arianti. Pendugaan Faktor Penentu Produksi Padi Sawah Sistem... 
produktif mempengaruhi kemampuan fisik petani dan cara berpikirnya. Penyerapan pengetahuan dan penerapan inovasi lebih baik pada orang-orang yang berusia produktif (Suharjo dan Patong, 1973 dalam Wulansari, 2010).

Pendidikan formal yang ditempuh responden rata-rata 8,25, 9,19 dan 8,50 tahun atau setara dengan pendidikan tamat SD dan SMP. Pendidikan akan mempengaruhi produktifitas petani karena pendidikan yang relatif rendah maka akan mempengaruhi kemampuan petani menyerap hal-hal baru. Namun di daerah penelitian petani padi pernah menerima pendidikan non formal berupa penyuluhan terutama tentang sistem tanam legowo. Penyuluhan pertanian yang diberikan membuka wawasan petani tentang berusahatani sehingga akan mempengaruhi kinerja mereka dalam meningkatkan produktifitasnya.

Jumlah anggota keluarga petani pada setiap tipe berkisar antara 4 sampai 5 orang. Jumlah anggota keluarga berusia produktif dapat menjadi tenaga kerja yang membantu dalam usahatani sehingga dapat meningkatkan produktifitas usahatani. Jumlah keluarga yang tidak berusia produktif menjadi tangggungan keluarga. Jumlah tanggungan keluarga ini mendorong petani sebagai kepala keluarga untuk dapat memenuhi kebutuhan keluarganya.

Pengalaman usahatani petani responden cukup lama, yakni rata-rata berkisar antara 11,50 untuk tipe 8:1 dan 19,17 tahun untuk tipe 4:1. Pengalaman petani responden cukup lama, sehingga mereka mangaplikasikan kemampuan mengelola usahatani lebih baik karena banyak belajar dari pengalaman yang diperoleh selama ini. Mata pencaharian sebagai petani padi sudah dilakukan secara turun temurun.

\section{Hasil Pendugaan Fungsi Produksi Padi Sawah Sistem Tanam Legowo}

Rata-rata penggunaan faktor produksi usahatani sistem tanam legowo di Kelurahan Dusun Besar Kecamatan Gading Cempaka Kota Bengkulu disajikan pada Tabel 2.

Tabel 2. Rata-rata Penggunaan Faktor Produksi Usaharani Sistem Tanam Legowo di Kelurahan Dusun Besar Kecamatan Gading Cempaka Kota Bengkulu

\begin{tabular}{clcccccc}
\hline \multirow{2}{*}{$\begin{array}{c}\text { F } \\
\text { o }\end{array}$} & Faktor Produksi & \multicolumn{2}{c}{ Tipe 4:1 } & \multicolumn{2}{c}{ Tipe 6:1 } & \multicolumn{2}{c}{ Tipe 8:1 } \\
\cline { 2 - 7 } & Per UT & Per Ha & Per UT & Per Ha & Per UT & Per Ha \\
\hline 1 & Luas lahan (Ha) & 0,71 & & 0,57 & & 0,61 & \\
2 & Benih (Kg) & 28,67 & 45,75 & 26,81 & 51,74 & 30,61 & 51,87 \\
3 & Pupuk Urea (Kg) & 75,00 & 105,63 & 66,35 & 125,64 & 77,78 & 135,19 \\
4 & Tenaga Kerja & 90,83 & 127,17 & 57,58 & 89,84 & 74,13 & 124,98 \\
& (HOK) & & & & & & \\
\hline
\end{tabular}

Sumber: Data diolah, 2011.

Hasil analisis data yang dilakukan menunjukkan hasil estimasi fungsi produksi padi sawah sistem legowo di Kelurahan Dusun Besar Kecamatan Gading Cempaka Kota Bengkulu seperti disajikan pada Tabel 3. 
Tabel 3. Hasil Estimasi Faktor-faktor yang Mempengaruhi Produksi Padi Sawah Sistem Tanam Legowo di Dusun Besar Kecamatan Gading Cempaka Kota Bengkulu

\begin{tabular}{llll}
\hline \multicolumn{1}{c}{ Variabel Bebas } & \multicolumn{1}{c}{ Koefisien Regresi } & Kesalahan Baku & t hitung \\
\hline 1. Luas lahan $\left(\mathrm{X}_{1}\right)$ & $0,24817 \mathrm{E}-05$ & $0,1531 \mathrm{E}-05$ & 1,621 \\
2. Jumlah benih $\left(\mathrm{X}_{2}\right)$ & $-0,10448$ & $0,3645 \mathrm{E}-01$ & $-2,866^{*}$ \\
3. Jumlah pupuk urea $\left(\mathrm{X}_{3}\right)$ & 0,56267 & 0,1104 & $5,098^{*}$ \\
4. Jumlah tenaga kerja $\left(\mathrm{X}_{4}\right)$ & 0,10873 & $0,7810 \mathrm{E}-01$ & 1,392 \\
5. Tipe legowo $4: 1\left(\mathrm{D}_{1}\right)$ & $0,38759 \mathrm{E}-02$ & $0,1330 \mathrm{E}-02$ & $2,914^{*}$ \\
6. Tipe legowo $6: 1\left(\mathrm{D}_{2}\right)$ & $0,18918 \mathrm{E}-02$ & $0,2441 \mathrm{E}-02$ & 0,775 \\
\hline Variabel terikat $(\mathrm{Y})$ & $=$ Produksi padi & & \\
Konstanta & $=5,8919$ & & \\
F hitung & $=43,811$ & & \\
F tabel & $=3,15$ & & \\
$\mathrm{t}$ tabel & $=2,021$ & & \\
$\mathrm{R}^{2}$ & $=0,8429$ & & \\
\hline
\end{tabular}

Keterangan : * : Nyata pada taraf kepercayaan $95 \%$

Sumber : Data diolah, 2011

Nilai koefisien determinasi $\left(R^{2}\right)$ yang diperoleh sebesar 0,8429 yang berarti bahwa $84,29 \%$ variasi produksi padi sawah sistem legowo dipengaruhi oleh variabel-variabel bebas dalam persamaan atau model, sisanya sebesar 0,1571 dipangaruhi oleh variabel-variabel lain yang tidak termasuk dalam model. Hasil Uji F pada taraf kepercayaan 95\% menunjukkan secara bersama-sama variabel bebas berpengaruh nyata terhadap variabel terikat. Hal ini ditunjukkan oleh nilai F hitung $(43,811)$ lebih besar dari nilai F Tabel $(3,15)$.

Adapun pengaruh masing-masing variabel bebas terhadap variabel terikat diuji dengan Uji t dan yang dapat dijelaskan sebagai berikut.

\section{Luas Lahan}

Petani padi legowo di daerah penelitian memiliki luas lahan 0,57 Ha untuk tipe 6:1, 0,61 untuk tipe 8:1 dan 0,71 Ha untuk tipe 4:1. Status lahan usahatani adalah lahan milik sendiri, dengan demikian mereka lebih leluasa mengelola usahatani di atas lahan sendiri. Variabel luas lahan yang dimaksud adalah luas lahan yang ditanami padi dengan sistem legowo.

Nilai koefisien regresi untuk luas lahan adalah 0,24817E-05 dan hasil uji t pada taraf kepercayaan 95\% menunjukkan bahwa luas lahan tidak berpengaruh terhadap produksi padi sistem legowo di Kelurahan Dusun Besar Kecamatan Gading Cempaka Kota Bengkulu, dimana nilai t hitung $(1,621)$ lebih kecil dari nilai $t$ tabel $(2,021)$ sehingga terima $\mathrm{H} 0$ dan Tolak $\mathrm{H} 1$.

Pada sistem tanam legowo yang dipentingkan adalah jarak tanam. Istilah legowo yang diambil dari Bahasa Jawa, Banyumas, terdiri atas kata lego dan dowo; lego berarti luas dan dowo berarti memanjang. Dengan cara tanam jajar legowo, kelompok-kelompok barisan tanaman padi dipisahkan oleh suatu lorong yang luas dan memanjang. Luas lahan tidak berpengaruh, yang berpengaruh adalah jarak tanam yang mencirikan tipe legowo yang digunakan, 
karena hal itu yang mempengaruhi intensitas cahaya matahari, kelembaban dan lain-lain yang berpengaruh kepada produksi padi.

\section{Jumlah Benih}

Benih yang digunakan dalam usahatani padi sistem legowo ini adalah jenis IR-64. Jumlah benih IR 64 yang direkomendasikan oleh BPTP (2007) adalah $30-35 \mathrm{~kg} / \mathrm{Ha}$. Sementara di daerah penelitian pada tipe 4:1 digunakan benih sebanyak 45,75 kg/Ha, tipe 6:1 sebanyak 51,74 kg/Ha dan tipe 8:1 sebanyak $51,87 \mathrm{~kg} / \mathrm{Ha}$ sehingga melebihi jumlah yang disarankan.

Nilai koefisien regresi yang diperoleh adalah sebesar -0,1044. Hasil uji t menunjukkan bahwa jumlah benih berpengaruh nyata negatif pada taraf kepercayaan $95 \%$ terhadap produksi padi sistem legowo yang ditunjukkan oleh nilai t hitung $(-2,866)$ lebih kecil dari nilai $t$ tabel $\quad(-2,021)$. Nilai koefisien 0,1044 memberikan arti bahwa kenaikan jumlah benih $1 \%$ akan menurunkan produksi padi sebesar 0,1044 \% atau sebaliknya, dengan asumsi variabelvariabel lain dianggap tetap.

Hal ini disebabkan oleh prinsip sistem tanam legowo yang memiliki jarak tanam yang pada setiap sejumlah barisan tertentu (jumlah barisan tergantung tipe legowonya) diselingi oleh satu barisan kosong sebagai lorong yang lebarnya dua kali jarak antar baris. Modifikasi jarak antar barisan dan dalam barisan ini berbeda dengan jarak tanam konvensional (tegel) yang tanpa lorong antar barisan. Tujuannya adalah agar sinar matahari dapat dimanfaatkan lebih banyak untuk proses fotosintesis, serangan hama, perkembangan penyakit dapat juga ditekan. Tidak hanya itu, pemupukan dan pengendalian organisme pengganggu tanaman menjadi lebih mudah dilakukan di dalam lorong-lorong (Anonima, 2011). Di daerah penelitian penambahan jumlah benih justru menyebabkan produksi padi menurun. Hal ini terjadi karena di daerah penelitian jumlah benih yang digunakan melebihi jumlah yang disarankan seperti telah dijelaskan di atas, sehingga keunggulan sistem tanam legowo justru tidak tercapai.

\section{Jumlah Pupuk Urea}

Jumlah pupuk urea yang digunakan di daerah penelitian, untuk tipe 4:1 sebanyak 105,63 kg/Ha, untuk tipe 6:1 sebanyak 125,64 kg/Ha dan untuk tipe $8: 1$ sebanyak $135,19 \mathrm{~kg} / \mathrm{Ha}$. Sementara jumlah yang direkomendasikan adalah $100 \mathrm{~kg} / \mathrm{Ha}$. Artinya petani responden menggunakan pupuk urea lebih banyak dari yang dianjurkan.

Nilai koefisien variabel jumlah pupuk urea sebesar 0,56267 dan berpengaruh nyata terhadap produksi padi sistem tanam legowo di daerah penelitian pada taraf kepercayaan 95\%, dimana hasil uji $\mathrm{t}$ menunjukkan nilai $\mathrm{t}$ hitung $(5,098)$ lebih besar dari $t$ tabel $(2,021)$. Jika jumlah pupuk urea ditingkatkan 1\% maka jumlah produksi padi akan meningkat sebesar 5,098\% atau sebaliknya dengan asumsi variabel lain dianggap tetap.

Dalam penanaman padi dengan sistem jajar legowo ini, pemupukan harus diperhatikan dengan baik. Seperti usahatani padi pada umumnya, pemupukan merupakan hal yang penting untuk menjamin ketersediaan unsur hara yang 
dibutuhkan tanaman untuk tumbuh, berkembang dan berproduksi dengan baik. Pada sistem tanam legowo penyerapan unsur hara berlangsung optimal karena kompetisi antar tanaman lebih sedikit dan ditambah lagi dengan jarak tanamnya yang termodivikasi sehingga penyerapan sinar matahari lebih baik dan metabolisme tanaman berlangsung maksimal yang pada akhirnya dapat memberikan hasil produksi yang maksimal.

Namun kondisi di lapangan menunjukkan petani menggunakan pupuk urea yang melebihi rekomendasi tetapi penggunaan pupuk sejumlah itu masih memberikan kenaikan hasil yang signifikan. Hal ini mungkin disebabkan oleh karena kondisi lahan persawahan di daerah penelitian masih membutuhkan unsur hara terutama yang dikandung pupuk urea dalam jumlah yang lebih banyak.

\section{Jumlah Tenaga Kerja}

Hasil analisis menunjukkan nilai koefisien regresi variabel tenaga kerja adalah sebesar 0,10873. Jumlah tenaga kerja ini tidak berpengaruh pada taraf kepercayaan $95 \%$ terhadap produksi padi legowo karena nilai $t$ hitung $(1,392)$ lebih kecil dari nilai $t$ tabel $(2,021)$. Dalam usahatani sistem legowo, karena jarak tanamnya yang diatur sedemikian rupa yang mempunyai lorong sehingga memberikan banyak keuntungan, maka kegiatan usahataninya membutuhkan tenaga kerja yang lebih sedikit (Anonima, 2011). Modifikasi jarak antar barisan dan dalam barisan disesuaikan untuk tujuan peningkatan populasi tanaman padi dan penciptaan iklim mikro yang tidak mengundang timbulnya hama dan penyakit (Anonim ${ }^{b}$, 2011). Penambahan ataupun pengurangan tenaga kerja dalam kegiatan usahatani sistem legowo tidak berpengaruh kepada hasil produksi karena tidak banyak kegiatan yang harus dilakukan tenagaa kerja terutama dalam hal penyiangan dan pengendalian hama dan penyakit.

\section{Tipe Legowo 4:1 (D1)}

Sistem tanam legowo tipe 4:1 artinya bila jarak tanam antar barisan yang digunakan adalah $25 \mathrm{~cm}$, sistem tanam jajar legowo 4:1 berarti setiap 4 barisan tanaman padi akan diselingi oleh 1 barisan kosong sebagai lorong yang lebarnya dua kali jarak antar baris sehingga luas lorong yang menyelingi adalah $50 \mathrm{~cm}$. Tipe jarak tanam ini merupakan inovasi dari jarak tanam tegel yaitu $25 \mathrm{~cm}$ (jarak antar barisan) x $25 \mathrm{~cm}$ (jarak dalam barisan); tanpa lorong yang menyelingi kelompok barisan tanam (Anonima, 2011). Modifikasi jarak antar barisan dan dalam barisan disesuaikan untuk tujuan peningkatan populasi tanaman padi dan penciptaan iklim mikro yang tidak mengundang timbulnya hama dan penyakit.

Nilai koefisien variabel tipe legowo 4:1 (D1) adalah sebesar 0,38759E-02 dan berpengaruh nyata pada taraf kepercayaan 95\% karena nilai thitung $(2,914)$ yang diperoleh lebih besar dari nilai $t$ tabel $(2,021)$. Nilai koefisien regresi bernilai positif berarti bahwa sistem tanam legowo 4:1 memberikan hasil produksi padi yang lebih baik atau lebih tinggi dibanding sistem tanam legowo lainnya (6:1 dan 8:1) dengan asumsi variabel lain dianggap tetap. Hal ini sejalan

16 | Nyayu Neti Arianti. Pendugaan Faktor Penentu Produksi Padi Sawah Sistem... 
dengan hasil penelitian yang dilakukan oleh Anonima (2011), bahwa tipe terbaik untuk mendapatkan produksi gabah tertinggi dicapai oleh tipe legowo 4:1.

\section{Tipe Legowo 6:1 (D2)}

Sistem tanam legowo 6:1 artinya bila jarak tanam antar barisan yang digunakan adalah $25 \mathrm{~cm}$, sistem tanam jajar legowo 6:1 berarti setiap 6 barisan tanaman padi akan diselingi oleh 1 barisan kosong sebagai lorong yang lebarnya dua kali jarak antar baris sehingga luas lorong yang menyelingi adalah $50 \mathrm{~cm}$. Tipe jarak tanam ini merupakan inovasi dari jarak tanam tegel yaitu $25 \mathrm{~cm}$ (jarak antar barisan) x $25 \mathrm{~cm}$ (jarak dalam barisan); tanpa lorong yang menyelingi kelompok barisan tanam (Anonima, 2011). Hasil analisis regresi menunjukkan nilai koefisien variabel sistem legowo 6:1 (D2) adalah 0,18918E-02 dengan nilai $t$ hitung sebesar 0,775 yang kecil dari nilai t tabel $(2,021)$, artinya variabel D2 tidak berpengaruh pada produksi padi sistem legowo di daerah penelitian. Hasil produksi padi tipe 6:1 tidak berbeda dengan tipe legowo lainnya. Hasil penelitian Wulansari (2010) menunjukkan bahwa produktifitas padi tipe legowo 6:1 tidak berbeda dengan produktifitas tipe legowo lainnya (4:1 dan 8:1).

\section{SIMPULAN DAN SARAN}

Dari hasil penelitian dan pembahasan dapat disimpulkan bahwa faktorfaktor yang berpengaruh terhadap produksi padi pada sistem tanam legowo di Kelurahan Dusun Besar Kecamatan Gading Cempaka Kota Bengkulu adalah jumlah benih dengan pengaruh negatif serta junlah pupuk urea dan tipe legowo 4:1 dengan pengaruh positif.

Berdasarkan hasil penelitian dapat diajukan saran berikut:

1. Penggunaan benih hendaknya sesuai dengan kebutuhan atau seseuai rekomendasi, karena penggunaan benih berlebih justru menyebabkan pemborosan dan juga menurunkan produksi padi,

2. Untuk meningkatkan produksi, maka pemberian pupuk urea harus tetap dilakukan karena pemberian pupuk urea meningkatkan produksi padi,

3. Para petani hendaknya menerapkan tipe legowo 4:1 karena terbukti memberikan produksi padi yang lebih tinggi dibanding tipe legowo lainnya (6:1 dan 8:1)

\section{DAFTAR PUSTAKA}

Anonima. 2011. Tanam Padi Sistem Legowo. http://www. handswo8.student. ipb.ac.id. Diunduh Tanggal 2 Januari 2011 Pukul 10.30 WIB.

Anonimb. 2011. Penanaman Padi Sistem Legowo. http://www.probolinggokab. go.id. Diunduh Tanggal 2 Januari 2011 Pukul 10.10 WIB.

Arianti, Nyayu Neti, Reswita dan Fristado. 2010. Analisis Fungsi Produksi dan Pendapatan Usahatani Padi pada Daerah Sentra dan Non-sentra di Kabupaten 
Lebong. Jurnal Agribis Volume II No 2 Juli 2010. Penerbit Fakultas Pertanian Univ. Muhammadiyah Bengkulu. Bengkulu.

Arifin, Bustanul. 2000. Pembangunan Pertanian: Paradigma, Kinerja, dan Opsi Kebijakan. INDEF. Jakarta.

Daniel, Moehar. 2002. Pengantar Ekonomi Pertanian. Bumi Aksara. Jakarta.

Nachrowi, Nachrowi Djalal dan Hardius Usman. 2008. Penggunaan Teknik Ekonometri: Pendekatan Populer dan Praktis Dilengkapi Teknik Analisis dan Pengolahan Data dengan Menggunakan Paket Program SPSS. Edisi Revisi. P.T. RajaGrafindo Persada. Jakarta.

Pindyck, Robert S. dan Daniel L. Rubinfeld. 1991. Econometric Models and Economic Forecasts. Third Edition. McGraw-Hill, Inc. Singapore.

Todaro, Michael P. dan Stephen C. Smith. 2003. Pembangunan Ekonomi di Dunia Ketiga. Edisi Kedelapan. Erlangga. Jakarta.

Wulansari, Shofur. 2010. Analisis Perbandingan Produktifitas Usahatani Padi Sawah pada Tiga Macam Sistem Tanam Legowo dan Kontribusinya terhadap Penerimaan Rumahtangga Petani (Studi Kasus di Kelurahan Dusun Besar Kecamatan Gading Cempaka Kota Bengkulu). Skripsi Jurusan Sosial Ekonomi Pertanian Fakultas Pertanian Universitas Bengkulu. Bengkulu. Tidak Dipublikasikan. 